\title{
Onipresença nos Conselhos Editoriais: Prestígio e Cerimonialismo na Atividade Científica
}

\author{
Luciano Rossoni \& Edson Ronaldo Guarido Filho - Universidade Positivo, \\ Curitiba (Brasil)
}

\section{Resumo}

O presente artigo analisou os conselhos editoriais de periódicos brasileiros a partir da noção de prestígio e da hipótese da onipresença subjacente às características de estratificação no campo científico. A amostra compreendeu 41 periódicos da área de Administração listados no sistema brasileiro de classificação de periódicos (Qualis/Capes). Assim, considerando-se as múltiplas afiliações de pesquisadores em conselhos editoriais, construímos a rede de relações entre periódicos e analisamos sua associação com indicadores de impacto e de qualidade atestada pelo sistema Qualis. Os resultados evidenciaram que periódicos com conselhos editoriais centralmente posicionados na estrutura de rede tenderam a ser mais bem avaliados no sistema Qualis e apresentaram maior percentual de citação. Concluímos o artigo discutindo aspectos ligados ao cerimonialismo presente na atividade do conselho editorial, tendo em vista o fato de que seu papel extrapola a atividade técnica de editoria, vinculando-se ao controle interno da ciência quanto à disseminação e certificação do conhecimento científico.

Palavras-chave: conselhos editoriais - prestígio - cerimonialismo - redes sociais

\begin{abstract}
This paper investigates the notion of prestige in editorial boards of Brazilian academic journals. It considers the ubiquity underlying the stratification characteristics of the scientific field. The sample included 41 journals in the business area, listed on the Brazilian system of journal classification (Qualis/Capes). We consider researchers' multiple memberships on editorial boards in order to map out the network among journals. Hence, by the means of network indicators we explore their relations with journal impact factor and quality certified by the Qualis system. The results showed a significant relationship between the position of editorial boards in the network structure and the ranking classification as measured by impact factor and Qualis systems. We conclude discussing the ceremonial aspects of editorial board. We argue that the role they played by editorial boards goes beyond the technical function of publishing, to be linked to their action as science gatekeepers.
\end{abstract}

Keywords: editorial boards - prestige - ceremonialism - social networks 


\section{Introdução}

Onipresente: 1. Que está ao mesmo tempo em toda a parte. 2. Que tem o dom da ubiqüidade (Dicionário Priberam, 2010).

A onipresença, a possibilidade de estar em todos os lugares ao mesmo tempo, é propriedade atribuída a seres divinos, não sendo tal potência conferida a seres humanos, pelo menos quando considerados em estado corpóreo. No entanto o processo de estratificação social inerente aos sistemas sociais tornou possível que um ator social assuma vários papéis em diferentes círculos sociais ou tenha a chance de exercer simultaneamente um mesmo papel social numa ampla variedade de entidades. Em certo sentido, essas condições propiciam uma espécie de onipresença. Todavia o envolvimento efetivo de qualquer agente humano aos seus diferentes espaços de atuação é limitado em razão de fatores como interesse, tempo e espaço, de tal modo que seu papel, em muitos casos, seja cerimonial.

As razões pelas quais o cerimonialismo é socialmente suportado decorrem da crença de que atores com alto prestígio são vistos como recursos para a legitimação de entidades às quais estão filiados. Logo, sua afiliação seria suficiente para atrair outros recursos, independentemente de qualquer relação com a efetividade do exercício de seu papel social. Denominamos metaforicamente esse fenômeno como "institucionalização" da onipresença que, no presente artigo, será tratado a partir da análise do campo científico, com especial atenção aos conselhos editoriais de periódicos ${ }^{1}$.

Periódicos e conselhos editoriais podem ser compreendidos como arranjos institucionais consagrados no sistema de comunicação científica moderno. Conforme explicitado por Lindsey (1976), grande parte do esforço acadêmico de pesquisadores se devota à publicação, já que, por um lado, isso aparece como importante fator para sua mobilidade no sistema de estratificação da ciência. Por outro, possibilita a divulgação de seus trabalhos, comunicando publicamente seus achados de pesquisa - fator que também está fortemente associado à lógica de recompensa e reconhecimento da ciência. Pelo fato de os periódicos terem grande importância no processo de difusão do conhecimento, especialmente no contexto atual da academia brasileira em administração, os conselhos editoriais surgem

\footnotetext{
${ }^{1}$ No sentido atribuído por Meyer e Rowan (1977), o fenômeno da onipresença pode ser visto como um mito racional, ou seja, um entendimento compartilhado quanto aos critérios de composição dos conselhos editoriais de modo a assegurar legitimidade do periódico perante a comunidade científica.
} 
como atores de relevância particular, conforme já anteciparam Kirschbaum e Mascarenhas (2009).

No sentido aqui adotado, conselhos editoriais representam um órgão normativo e consultivo com a função de regulamentar, referendar e qualificar a política editorial dos respectivos periódicos científicos. Ao menos num sentido ideal, exercem papel que vai além da atividade técnica de editoria, na medida que sua composição e a atuação de seus membros conselheiros trazem implicações no conhecimento científico. São arranjos vinculados à disseminação do conhecimento e, mais do que isso, e de forma essencial, estão associados à certificação do conhecimento válido, que, por essas razões, possuem implicações sobre as instituições da ciência. Diante disso, o objetivo do presente artigo é analisar a associação dos indicadores de qualidade e de citações dos periódicos brasileiros da área de administração com a composição e estrutura relacional de seus conselhos editoriais.

Em face do exposto, em um primeiro momento, tratamos do sistema de comunicação científica, dando ênfase ao papel dos periódicos enquanto instituição social vinculada a valores do ethos científico. Posteriormente, exploramos o papel de gatekeepers dos conselhos editoriais, na medida que podem representar arranjos institucionais vinculados à estrutura normativa da ciência. Na sequência, discutimos implicações da análise de conselhos editoriais sobre temas como legitimidade e prestígio, ambos tratados sob a ótica dos periódicos. A seguir, apresentamos os procedimentos metodológicos utilizados na parte empírica deste trabalho para depois expormos a análise dos dados referentes ao relacionamento entre membros de conselhos editoriais, periódicos e atributos de afiliação acadêmica. Concluímos o artigo discutindo as implicações das análises no processo de seleção de conselheiros editoriais.

\section{Periódicos, Ethos e Comunicação Científica}

Periódicos científicos, na forma como conhecemos atualmente, são um fenômeno histórico intrinsecamente associado à institucionalização da ciência enquanto esfera de conhecimento legítima na sociedade moderna. Meadows (1998) explica que periódicos acadêmicos tiveram origem no século XVII com o intuito de formalmente comunicar os fatos, opiniões, estudos e outros aspectos de interesse. Os journals, ou periódicos, como chamamos em português, resultam de transformações sociais ligadas à substituição de modos informais de comunicação de pesquisa por outros de natureza formal que ampliassem 0 acesso e o escopo das audiências interessadas. Mais do que isso, o significado desse tipo de publicação foi 
gradualmente se aproximando do que hoje Ihe atribuímos. Ao longo da história, periódicos científicos, em essência, passaram a ser reconhecidos como "a serious publication containing original thought" (Meadows, 1998, p. 7), com publicação regular e conteúdo formado por artigos compostos por diferentes autores (Meadows, 1998).

As transformações ocorridas a partir do século XVII tiveram como base os princípios iluministas associados a um processo mais amplo de racionalização da sociedade (Weber, 1996). A valorização da razão e do conhecimento racional como modo de compreender o mundo trouxe como componente agregado a noção de que não há monopólio sobre o conhecimento, depondo contra as bases institucionais tradicionais da sociedade. De um lado, esse processo evidenciou transformações sociais em favor de modos alternativos de conhecimento, em adição aquele de caráter essencialmente religioso. Por outro, promoveu a visão de que o conhecimento pode ser acumulado, consagrando a esfera científica como forma legítima de prover o entendimento sobre o mundo. Nesse contexto, questões associadas à comunicação, troca e difusão de informações acerca de trabalhos produzidos passam a ser consideradas, especialmente no que tange à durabilidade e disponibilidade do conhecimento criado ao longo da atividade científica. Assim, a gradual ascensão de periódicos passou a ter um papel fundamental na comunicação formal do conhecimento complementando, ampliando e, em certa medida, substituindo os canais tradicionais de comunicação das pesquisas, como livros, exposições orais ou trocas de correspondências (Meadows, 1998).

Contudo a relação dos periódicos com o sistema de comunicação acadêmica vai além da expressão formal e durável do conhecimento. De acordo com Merton (1996), a ciência se consolidou enquanto esfera relativamente autônoma na medida em que gradativamente desenvolveu seu ethos, ou seja, um conjunto de imperativos normativos, legitimados na forma de valores e normas institucionais ${ }^{2}$. Esse complexo conjunto de valores e normas sociais define a estrutura culturalnormativa da prática científica, fornecendo as bases para a organização e continuidade da ciência enquanto sistema social particular, sob o qual se processa e legitima a conduta dos cientistas e sem o qual o conhecimento válido não seria possível (Merton, 1996). Disso decorre que a atividade científica não se dá num vácuo social, mas imersa em uma comunidade de cientistas na qual são

\footnotetext{
${ }^{2}$ Os valores do ethos científico são mais bem compreendidos como ideais para a prática científica (Cole, 2004), de modo que seu significado está mais para o entendimento da estrutura de valores que confere legitimidade à conduta científica do que para motivações e percepções ambivalentes presentes no comportamento individual de pesquisadores.
} 
compartilhados princípios que norteiam e justificam as ações, tal como possibilitam o reconhecimento e a validação do conhecimento (Cronin, 1984).

O reconhecimento público quanto à contribuição de uma pesquisa para o corpo de conhecimento de uma área é a expressão do sistema de recompensa na ciência. Tal reconhecimento está fortemente vinculado ao modo como o conhecimento é transmitido à comunidade científica, cujo papel de destaque é atribuído à publicação em periódicos (Crane, 1967; Cronin, 1984; Merton, 1996; Whitley, 1970). De acordo com Cronin (1984), periódicos são o meio por excelência do sistema de comunicação científica, por meio dos quais são trocadas informações e forjados os reconhecimentos. Periódicos possuem papel especialmente relevante não apenas enquanto repositórios de ideias, mas como instrumentos de preservação da confiabilidade e autenticação do conhecimento científico (Machadoda-Silva, Guarido Filho, Rossoni \& Graeff, 2008). Por conseguinte, atuam como veículos para se alcançar visibilidade profissional e institucional, fornecendo prestígio aos pesquisadores e ao próprio periódico, uma vez que o compartilhamento e a divulgação das informações de natureza científica ocorrem por meio deles (Moed, 2005; Rousseau, 2002). Nas palavras de Bedeian (2003, p. 337),

"scientific journals are keystones in the edifice of any serious discipline. They serve as the published record of a discipline's accomplishments and determine the general course of its advancement. Publication is likewise a key ingredient in a successful academic career, influencing who gets promoted, who gets grants, and who advances professionally."

Diante do exposto, as práticas sociais na atividade científica e sua expressão materializada na publicação em periódicos se assenta, ao mesmo tempo que reforça, uma cultura acadêmica que se estende para além das prescrições técnicas ou metodológicas. Em última instância, vinculam-se ao que Merton (1996) aponta como o objetivo institucional da ciência, qual seja a extensão do conhecimento certificado, cujos arranjos institucionais estão organizadas em favor deste objetivo (ao menos num sentido ideal). Esse é o caso dos conselhos editoriais, alvo da próxima seção.

\section{Conselhos Editoriais}

Nem tudo o que se produz na academia é efetivamente publicado nos canais de comunicação científica. No caso dos periódicos, o papel dos conselhos editoriais é vital no exercício da sanção social para os produtos da academia conforme elaborados por seus autores. De acordo com Hames (2001) e Parker (2007), conselhos editoriais de periódicos acadêmicos possuem, ainda que com alguma 
variação, pelo menos quatro papéis centrais: (i) aconselhar e decidir sobre a política editorial, (ii) promover amplamente o periódico, (iii) solicitar e encorajar a submissão de manuscritos, procurando atrair os melhores trabalhos, e (iv) avaliar a adequação dos manuscritos à linha editorial e exercer a revisão dos trabalhos em conformidade com a prática de peer review. Contudo, conforme destacam Parker (2007) e Bedeian, Fleet e Hyman (2009), o significado de sua atuação se estende para além desses aspectos mais evidentes associados à instrumentalidade da função exercida.

Considerados amplamente, conselhos editoriais exercem um duplo papel na compreensão da ciência enquanto sistema social. Por um lado, são atores no processo de validação do conhecimento científico exercendo a função de mediação do conhecimento na promoção diferentes oportunidades para publicação (Crane, 1967). Por outro, representam arranjos institucionais associados às estruturas normativas da ciência na medida que estão vinculados a práticas sociais ligadas aos valores do ethos científico, especialmente o ceticismo organizado e o universalismo (Bedeian, 2003, 2004; Bedeian et al., 2009; Meadows, 1998). Enquanto o primeiro papel está relacionado com a estratificação na ciência, o segundo está ligado às suas estruturas institucionais.

Lindsey (1976, p. 804) expressa bem essa conjunção ao afirmar que:

"scientific craftspersons, charlatans, practitioners, scholars, and others are engaged in the creation of social science knowledge. However, not all of the products these individuals create receive societal sanction. The primary social institution responsible for processing and evaluating contributions to knowledge is the professional journal. The editorial review board of the professional journal confers authority and legitimacy upon the contributions to knowledge it selects for publication."

Enquanto mediadores do conhecimento, normalmente se atribui aos conselhos editoriais o papel de guardiões da pesquisa ou gatekeepers da ciência. Como tais, atuam como protetores da literatura ou intérpretes institucionalizados, que analisam e autorizam a circulação da informação entre os membros de uma determinada área (Crane, 1967; Fogarty \& Liao, 2009; Lindsey \& Lindsey, 1978; Parker, 2007; Rynes, 2006; Whitley, 1970) e, portanto, estão associados ao ceticismo organizado da ciência, participando dos julgamentos de qualidade do conhecimento certificado (Meadows, 1998). De acordo com Lindsey e Lindsey (1978), essa função estaria intimamente relacionada ao sistema de estratificação social da ciência, já que suas decisões em favor de publicações possuiriam conseqüências sobre a carreira de pesquisadores, simultaneamente influindo sobre 
aspectos associados à qualidade e produtividade. Mais do que isso, sua institucionalização enquanto gatekeepers traz implicações sobre a vitalidade intelectual de uma disciplina, bem como acerca de seu futuro (Bedeian, 2003; Bedeian et al., 2009), com grande relevância para a validação e construção da base de conhecimento científico (Bedeian, 2004; Crane, 1967). Vistos dessa forma, não é possível atribuir aos conselhos editoriais a atividade de revisores técnicos. Como explica Parker (2007), conselhos editoriais possuem a responsabilidade de desafiar, criticar e debater a própria academia.

Contudo muito do que se tratou até esse ponto consiste em aspectos ideais, nem sempre constatados empiricamente. Por exemplo, questões ligadas à legitimidade da autoridade de conselhos editoriais têm sido recorrentes na literatura. Uma razão para isso tem relação com o que Cole e Cole (1973) e Kuhn (1970) já haviam se pronunciado no passado: a expectativa de que a certificação do conhecimento seja realizada por pares competentes, de modo que a autoridade exercida por eles seja reconhecida como legítima pela comunidade científica. Tal fato abre uma série de questões acerca dos papéis exercidos pelos conselhos editoriais, no entanto é o debate acerca da seleção de conselheiros que ganha proeminência na literatura, passando por aspectos ligados à diversidade (p. ex. Addis \& Villa, 2003), representatividade internacional (p. ex. Buena-Casal, Perakakis, Taylor \& Cheka, 2006; Ozbilgin, 2004; Tutarel, 2004), expertise acadêmica (p. ex. Crandall, 1977; Gilbert, 1977; Lindsey, 1976; Weinrach, 2006) e reputação (p. ex. Feldman, 2008). Para os fins deste trabalho, os dois últimos serão tratados a seguir.

\section{Prestígio, Legitimidade e Conselhos Editoriais}

Os aspectos tratados nos tópicos precedentes acerca do papel do conselho editorial chamam atenção para o fato de exercerem grande influência sobre a trajetória e parâmetros para o conhecimento num determinado campo. Em consonância com Cole e Cole (1973) e Kuhn (1970), em face de sua posição como gatekeepers, seria esperado que a expertise dos membros de conselhos editoriais fosse requisito necessário para a definição dos caminhos para onde a academia deveria seguir (Bedeian et al., 2009). Nesse sentido, assegurariam legitimidade à sua autoridade perante a comunidade acadêmica e promoveriam um sistema de comunicação científica rigoroso e íntegro.

Contudo a consideração de expertise acadêmica é assunto bastante controverso. Lindsey (1976), por exemplo, considerou a produtividade acadêmica como critério de competência para seleção dos membros do conselho editorial, aspecto que mais 
tarde, foi reconcebido por Pardeck et al. (1991), que consideram o volume de citações recebidas por membros do conselho editorial. Em ambos os casos, o debate se deu em torno da atribuição de distinção acadêmica a um único fator. Gilbert (1977) e Crandall (1977) foram autores contrários à posição metodológica de Lindsey (1976), defendendo que há ampla variedade de indicadores que podem atestar sua competência enquanto membro de conselho editorial, como por exemplo, o status social, a prática profissional no campo, a habilidade técnica de conduzir o trabalho de revisão ou editoria. Hitt (2009), por exemplo, aponta que a expertise, enquanto critério de seleção, deve considerar não apenas a profundidade do conhecimento, mas também a experiência dos membros do conselho e sua receptividade a novas ideias e abordagens. Pontos similares são defendidos por Reynes (2006) e Daft e Lewin (2006), que ressaltam que os conselhos podem influenciar na abertura de espaço para a novidade quanto ao que é tratado teórica e empiricamente num determinado campo. Winrach et al. (2006, p. 305) sintetizam essas questões, mas trazem um ponto adicional. Segundo os autores, "it may be assumed that they have some combination of outstanding academic reputations or that they bring special expertise to the respective editorial boards".

A questão da reputação dos conselheiros é também apontada por Zdeck (2008) como critério relevante para sua indicação como membro de conselho editorial. Para ele, a reputação se dá em termos de opiniões e indicações de colegas na academia que reconhecem o conhecimento do pesquisador e, se for o caso, sua atuação prévia como conselheiro ${ }^{3}$. Nesse sentido, o ponto relevante está associado à transferência de reputação do conselheiro para o periódico para o qual está vinculado.

Um aspecto adicional ainda associado à relação entre reputação e conselhos editoriais pode ser visto não mais sob a ótica do periódico, mas dos programas de pós-graduação. Desde Kaufman (1984), uma série de trabalhos em diferentes áreas do conhecimento tem se dedicado a promover rankings de escolas com base na representação de seus acadêmicos em conselhos editoriais de periódicos científicos. Nesses estudos, parte-se do pressuposto de que fazer parte do quadro de conselheiros reflete a confiança e a posição de destaque atribuída a um

\footnotetext{
3 Há vários trabalhos que tratam do prestígio conquistado por acadêmicos ao se vincularem como membros de conselho, agregando do ponto de vista individual uma série de benefícios que vão do reconhecimento público, formação de redes de relacionamento, troca de informações, contribuição com o empreendimento acadêmico, aprendizado, ou mesmo status de pertencer a um círculo restrito (Addis \& Villa, 2003; Fogarty \& Liao, 2009; Parker, 2007). Embora esse não seja o foco do presente estudo, cabe mencionar que aspectos disfuncionais ou perniciosos podem decorrer do fechamento do círculo de gatekeepers, da ausência de imparcialidade e da sobreposição de ambições pessoais às prerrogativas do conhecimento científico.
} 
pesquisador por seus pares, o que, por meio de mecanismos de transferência de prestígio, influenciariam a qualidade percebida de departamentos, universidades ou programas de pós-graduação (vide p. ex. Chan, Fung \& Lai, 2005; Hardim et al., 2006; Kaufman, 1984; Mittermaier, 1991).

De modo similar, Feldman (2008) e Hames (2001) constataram que periódicos novos tentam atrair acadêmicos com reputação mais consolidada no campo, geralmente advindos de instituições prestigiadas, de modo a ganhar legitimidade institucional. Acredita-se que a composição do conselho pode exercer influência sobre a audiência, especialmente no que tange ao volume e qualidade percebida dos artigos submetidos (Hames, 2001; Whitley, 1970; Zdeck, 2008). Esse raciocínio também se faz presente no Brasil, onde, até o presente momento, a avaliação de qualidade de periódicos considera características dos conselhos editoriais, como diversidade e expertise do quadro de conselheiros (vide Coordenação de Aperfeiçoamento de Pessoal de Nível Superior [Capes], 2007).

Em face desses apontamentos acerca do processo de seleção dos conselheiros editoriais de periódicos, buscamos neste trabalho enfatizar os aspectos relacionais envolvidos em sua atividade, tendo em vista seu componente simbólico. Isso porque entendemos que o processo de composição de conselhos editoriais remete a questões sociais e institucionais que vão além da dimensão objetiva da atividade científica. Ele também aponta para escolhas sustentadas em duas razões: instrumental e social. Na concepção de Blau (1962), escolhas instrumentais são guiadas tomando como referência o fato de que as relações podem representar meios para se alcançar um determinado objetivo, enquanto em escolhas sociais os relacionamentos não são considerados meios, mas fins em si mesmos e, portanto, a própria razão da relação.

Na lógica relacional dos conselhos editoriais, o tipo de escolha instrumental pode ser desdobrado em dois mecanismos: um que envolve escolhas baseadas em aspectos utilitários, pautado fundamentalmente na crença da capacidade técnica do conselheiro; outro que envolve aspectos institucionais, calcada na reputação e prestígio de alguns pares, cuja função é a de legitimar o conselho editorial. Já o tipo de escolha social envolve basicamente o processo de seleção dos pares a partir da afinidade entre eles.

Diante disto, buscamos neste trabalho categorizar os periódicos com base em sua classificação no sistema brasileiro de estratificação de periódicos (Qualis/Capes) e, a partir disso, avaliamos os padrões de homofilia e heterofilia tomando-se como base o compartilhamento de conselheiros editoriais. O princípio da homofilia diz 
respeito ao fato de que o contado entre indivíduos acontece em maior grau com aqueles que apresentam características similares (McPhearson, Smith-Lovin \& Cook, 2001), de tal modo que a justificativa para a criação e conservação de relacionamentos se dá justamente pelo reconhecimento de similaridade em termos de posição, entidade ou classe pelos diferentes indivíduos. Do contrário, em relações de heterofilia, é a diferenciação, ou seja, a posse de características ou atributos distintos, que funciona como elemento atrativo nas relações (vide Blau, 1962; McPhearson et al., 2001). já que pressupomos que esta classificação remeta ao status diferenciado que esses apresentam na academia brasileira de administração.

Adicionalmente, avaliamos como a posição diferenciada dos conselhos editoriais está relacionada com a qualidade atribuída aos periódicos. Com isso, destacamos a questão da escolha preferencial, o que remete a possibilidade de onipresença de alguns conselheiros, tal como de algumas instituições. Na linguagem relacional, isso se refere ao prestígio de um ator. Um ator de prestígio é aquele que possui maior atratividade nas relações, ou seja, é foco de maior quantidade de laços diretos ou indiretos que os demais (Faust \& Wasserman, 1992).

\section{Procedimentos Metodológicos}

\section{Dados e Amostra}

De um total de 837 periódicos listados em 2008 na área de Administração no sistema brasileiro de estratificação de periódicos ${ }^{4}$ (Qualis/CAPES), excluímos aqueles que se enquadravam em um dos seguintes critérios: eram editados no exterior; estavam classificados como C; não tinham linha editorial predominantemente vinculada à área de administração. Dos 51 periódicos remanescentes, três eram registros duplicados, um parou de ser editado, dois não apresentavam conselho editorial e quatro não apresentavam meios de acesso eletrônico às informações editoriais. Sendo assim, a amostra compreendeu um total de 41 periódicos (vide Apêndice A). Para cada um deles, identificamos todos os conselheiros editoriais, não fazendo distinção se eram denominados como

\footnotetext{
${ }^{4}$ O sistema brasileiro de estratificação de periódicos, denominado Qualis, é mantido pela Coordenação de Aperfeiçoamento de Pessoal de Nível Superior (Capes), órgão regulador da pós-graduação stricto sensu no Brasil. No sistema Qualis, os periódicos científicos são classificados em diferentes níveis, variando de $\mathrm{A} 1$ até $\mathrm{C}$, a partir de critérios como: composição do conselho editorial, endogenia da produção, gestão editorial, indexação, entre outros. Cada nível se converte numa escala de pontos que, nas áreas do conhecimento em estudo neste artigo, varia de 0 (Qualis C) a 100 (Qualis A1). Essa pontuação é relevante, pois serve de referência para a avaliação da qualidade da produção científica de pesquisadores e programas de pós-graduação brasileiros. Por essa razão, é dada prioridade para a produção em periódicos de estratos superiores.
} 
conselheiros editoriais, científicos ou de política editorial. Adicionalmente, registramos a instituição de origem do conselheiro, e outros dados tais como a unidade federativa e/ou país de origem à época da coleta dos dados.

\section{Rede de Relações entre Conselhos de Periódicos}

Tendo em vista que a consecução do objetivo do presente artigo envolve o mapeamento das relações entre periódicos, optamos por construir a rede de relações entre os diferentes conselhos editoriais. Para tanto, seguindo as orientações de Wasserman e Faust (1994), transformamos a matriz de incidência entre periódicos e seus respectivos conselheiros (rede two-mode) em matriz quadrada, na qual cada célula passou a indicar o volume de ocorrências de compartilhamento de conselheiros para cada um dos diferentes pares de periódicos (rede one-mode). Graficamente, conforme representado na Figura 1, cada nó representa um único periódico e os laços indicam a existência de pelo menos um conselheiro em comum. Utilizamos os softwares UCINET e PAJEK para gerar as matrizes, tal como todos os indicadores relacionais.

\section{Variáveis}

Foram utilizadas duas categorias de variáveis: composicionais e relacionais (vide Wasserman \& Faust, 1994), respectivamente referentes a atributos inerentes a cada periódico e às métricas auferidas por meio da análise relacional dos conselhos de periódicos.

\section{Variáveis Composicionais}

Idade. Tempo de existência do periódico calculado a partir do ano de sua primeira publicação. Nos casos em que houve interrupção por períodos longos de tempo, consideramos como início o ano de retomada da regularidade da publicação.

Número de Conselheiros. Calculado a partir do somatório de conselheiros editoriais declarados pelos periódicos. Não foram considerados conselheiros os editores ou avaliadores ad hoc.

Endogenia. Refere-se à proporção, em termos percentuais, de membros do conselho editorial de determinado periódico que simultaneamente integram o quadro funcional da respectiva instituição responsável por sua edição.

Internacionalização. Refere-se à proporção, em termos percentuais, de conselheiros de um determinado periódico que são filiados a instituições de ensino e pesquisa sediadas no exterior. 
Qualis. Refere-se ao conceito dos periódicos de acordo com o sistema brasileiro de estratificação de periódicos (Qualis/Capes), segundo uma escala ordinal que vai de A1 a C. No presente artigo, não foram considerados os periódicos classificados no estrato $C$ e, devido ao número pequeno de casos, os periódicos foram agrupados em quatro categorias: (4) A2-B1; (3) B2; (2) B3; (1) B4-B5. Sendo assim, quanto maior o valor da escala ordinal, maior a classificação no Qualis/Capes do periódico. Destacamos que não houve na amostra periódicos brasileiros classificados como A1.

Fator de Impacto (FI). Calculado a partir da razão entre citações (C) e artigos publicados $(\mathrm{N})$, para uma janela temporal de dois anos, conforme a fórmula $\mathrm{FI}=\mathrm{C} / \mathrm{N}$. Assim, o cálculo do fator de impacto de um periódico para o ano de 2007, por exemplo, considera no numerador o volume de citações no ano em questão para qualquer item publicado no periódico nos dois anos anteriores, enquanto no denominador está o montante de artigos publicados pelo periódico nesses mesmos dois anos (Garfield, 1972). Devido a ausência de informações sistemáticas a esse respeito no Brasil, os dados acerca do FI dos periódicos componentes da amostra foram obtidos de Machado-da-Silva et al. (2008), considerando-se a média dos FI's dos anos de 2005, 2006 e 2007.

\section{Variáveis Relacionais}

Degree. A centralidade de grau (degree) é medida pelo número de laços que um ator possui com outros atores em uma rede, podendo indicar proeminência ou prestígio dos atores sociais dentro da rede social (Wasserman \& Faust, 1994). No presente artigo, refere-se ao número de laços que um periódico estabelece com outros, a partir da existência de conselheiros editoriais em comum.

Betweenness. Medida que avalia a quantidade de intermediações que um ator faz numa rede (Wasserman \& Faust, 1994). Assim, quanto maior a capacidade de um ator conectar dois atores não diretamente conectados, maior sua centralidade de intermediação (betweenness). A existência de intermediação de relações entre periódico pode ser indicativo da capacidade do conselho em ter acesso privilegiado à informação, assim como evidencia posição central na rede. Por essas razões, acreditamos que conselhos com maior capacidade de intermediação tenham melhor avaliação da qualidade.

Closeness. Medida que avalia a proximidade ou distância de um ator em relação aos demais, obtida a partir da soma das distâncias geodésicas entre um periódico e todos os outros da rede (farness, como explicitado por Wasserman \& Faust, 1994). No entanto, como a distância tende a diminuir com o aumento da centralidade, o 
indicador de centralidade de proximidade é ponderado inversamente ([farness/n1]-1), gerando a medida closeness (Faust \& Wasserman, 1992).

Densidade do Conselho Editorial dos Periódicos. Indicador do número médio de participações dos conselheiros de um periódico em quaisquer dos outros conselhos editoriais integrantes da amostra. Quanto maior o número de conselhos que, em média, os conselheiros de um determinado periódico participam, maior a densidade daquele conselho editorial. Adicionalmente, tendo em vista que os conselheiros variam em termos do número de participações em conselhos, foi também calculado o desvio padrão da densidade do conselho editorial de cada periódico. No contexto do atual sistema de estratificação de periódicos no Brasil, tal medida pode ser auxiliar na indicação de que periódicos podem fazer uso de conselheiros mais centrais, ou seja, presentes em vários outros conselhos, como forma de se legitimar.

\section{Métodos de Análise}

Blockmodels. O procedimento de blockmodels é útil quando se deseja agrupar os relacionamentos em categorias mais abrangentes, objetivando avaliar padrões de relacionamento entre elas, como no caso dos periódicos agrupados em termos de sua classificação pré-existente no sistema Qualis/Capes. Para tanto, elaboramos a matriz densidade considerando os relacionamentos intra e entre categorias. Nesta matriz, os nós não representam periódicos, mas os diferentes estratos do Qualis. Depois disso, criamos uma matriz imagem a partir do critério de densidade $\alpha$, em que se considera que existe uma relação entre categorias somente quando sua densidade é maior ou igual à densidade média da rede como um todo (Wasserman \& Faust, 1994). A partir dela, ilustramos as relações por meio do software PAJEK.

E-I Index. A fim de verificar os padrões de relacionamento entre os estratos Qualis, utilizamos o indicador E-I Index (Krackhardt \& Stern, 1988), gerado a partir do UCINET. Este indicador permitiu avaliar a quantidade e a densidade de laços intra e entre as categorias de periódicos. Da comparação entre o volume de laços internos e externos em relação ao total, é gerado um índice para cada uma das categorias, assim como para toda a rede, cuja amplitude varia de -1 a 1 : valores mais próximos de 1 indicam tendência de relacionamentos externos, ou seja, entre categorias diferentes, enquanto valores mais próximos a -1 revelam propensão de estabelecimento de relacionamentos internos à própria partição.

Teste ANOVA. Para avaliar o quanto a classificação no Qualis condiciona os indicadores relacionais dos periódicos, tal como o grau de internacionalização e endogenia, comparamos a média de cada um deles por meio do teste ANOVA, 
disponível no SPSS. Adicionalmente, apresentamos a variância explicada pelas categorias utilizadas por meio do $\mathrm{Eta}^{2}$, que pode ser interpretado em termos percentuais.

Correlação de Pearson. Para analisar quais elementos estão relacionados com a centralidade dos periódicos, com a classificação no Qualis e com o Fator de Impacto, utilizamos o teste de correlação de Pearson, gerado a partir do software SPSS. Não utilizamos modelos multivariados de regressão, devido ao número pequeno de casos, tal como a problemas de colinearidade das variáveis ocasionados por sua origem relacional.

\section{Resultados}

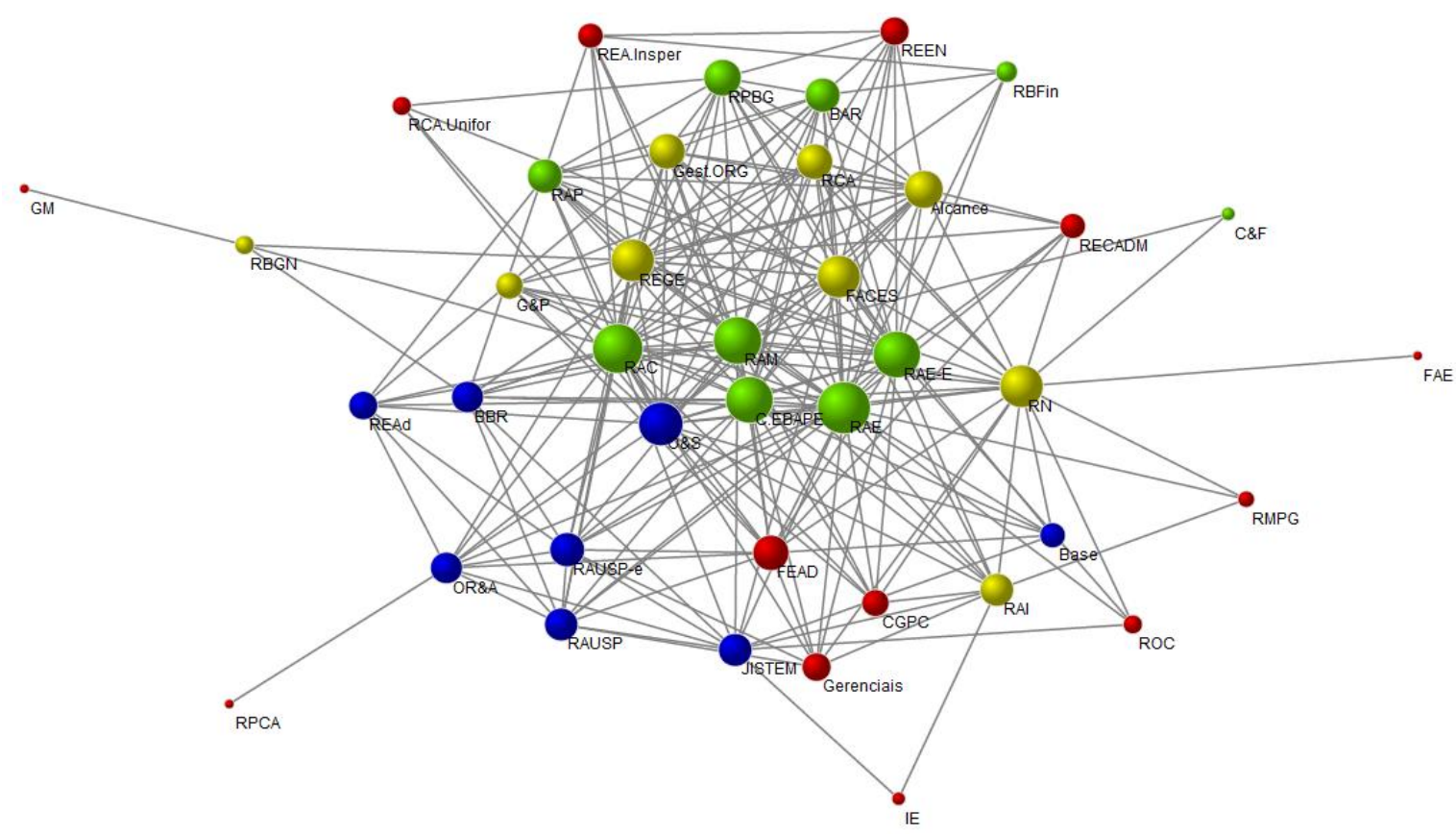

Figura 1. Rede de Relações entre os Conselhos Editoriais dos Periódicos.

A estrutura de relações entre periódicos brasileiros em administração constituída por meio da análise da composição de seus conselhos editoriais está representada na Figura 1. Nela, cada nó representa um periódico, cujas cores e tamanho indicam, respectivamente, sua classificação no sistema de estratificação Qualis/Capes (verde = A2-B1; azul = B2; amarelo = B3; vermelho $=\mathrm{B} 4-\mathrm{B} 5$ ) e $\mathrm{a}$ quantidade de laços com outros periódicos a partir da existência de conselheiros compartilhados. Assim, quanto mais relações com outros periódicos, maior o tamanho do nó. Tal estrutura reticular é moderadamente densa $(28,8 \%)$ e coesa (coeficiente de agrupamento $=0,673$ ), de modo que, em média, cada um dos periódicos compartilha 24,83 conselheiros com os demais, envolvendo neste 
compartilhamento, em média, 11,51 periódicos. Isso lhes permite estarem próximos uns dos outros (distância média $=1,85$ passos), conforme visualizado na Figura 1.

Entre os 41 conselhos editoriais investigados, identificamos 260 entidades, entre governos, empresas e instituições de ensino, envolvidas nas afiliações de 731 conselheiros, os quais constituíram um total de 1.008 relacionamentos com periódicos, gerando uma média de 24,58 conselheiros por periódico. Como há vários casos em que conselheiros participam de mais de um periódico, o somatório de conselheiros das revistas é maior que o número total de conselheiros identificados. A Tabela 1 sintetiza essas informações.

\begin{tabular}{lclc}
\hline \multicolumn{1}{c}{ Estatísticas Descritivas } & \multicolumn{2}{c}{ Estatísticas da Rede } \\
\hline Periódicos & 41 & Densidade & $28,8 \%$ \\
IES e Organizações & 260 & Número de Laços & 472 \\
Conselheiros & 731 & Média de Laços por Periódico & 11,51 \\
Relações Periódico x Conselheiro & 1.008 & Frequência Média de Relações & 24,83 \\
Média de Conselheiros & 24,58 & Distância Média & 1,85 \\
Internacionalização Média & $22,12 \%$ & Diâmetro & 4 \\
Endogenia Média & $17,75 \%$ & Coeficiente de Agrupamento & 0,673 \\
\hline
\end{tabular}

Tabela 1. Estatísticas Descritivas dos Conselhos e da Rede de Relações dos Periódicos.

Quanto à composição dos conselhos editoriais, os periódicos apresentaram grau de internacionalização de $22 \%$, e baixo grau de endogenia com uma média de $17,75 \%$ de conselheiros fazendo parte simultaneamente do quadro funcional da mesma instituição que edita o periódico. Apesar de não ser uma taxa alta de endogenia, alguns casos apresentaram indicadores bem mais acentuados como, por exemplo, os periódicos RAUSP (57\%), RAUSP-e (54\%) e REGE ( $41 \%)$, todos editados pela Universidade de São Paulo, e Gestão.ORG (55\%), editado pela Universidade Federal de Pernambuco. Com relação à internacionalização, conforme se poderia prever, esse índice foi mais elevado nos conselhos de periódicos com foco internacional como nos casos da Brazilian Adminstration Review (BAR), com 89\%, da Brazilian Business Review (BBR), com 50\%, do Journal of Information Systems and Technology Management (JISTEM), com 54\%, e da Revista Brasileira e Portuguesa de Gestão, publicação luso-brasileira, com 73\%.

A composição dos conselhos dos periódicos destaca a atenção atribuída aos critérios de diversidade exigidos pelo sistema Qualis/Capes no sentido de estarem compostos por conselheiros de pelo menos três instituições distintas. Além disso, as características da composição dos conselhos, em alguns casos, indicam desejo de repercutirem internacionalmente, na medida que incorporam membros de instituições estrangeiras. 
Apesar de esses pontos estarem de acordo com exigências de qualidade impostas sobre a gestão dos periódicos em análise, nosso interesse na presente pesquisa extrapola esses aspectos descritivos, na medida que trata do caráter simbólico do conselho editorial, vinculado à sua legitimidade perante a comunidade acadêmica. Com vistas a melhor compreender esse aspecto, para o qual associamos a ideia de onipresença, na sequência, analisamos os periódicos brasileiros da área de administração a partir da composição de seus conselhos editoriais.

\section{Influência da Centralidade na Classificação Qualis e Fator de Impacto}

Como destacamos no quadro teórico, partimos do pressuposto de que os periódicos, por razões instrumentais, buscam legitimar sua atuação incorporando acadêmicos de prestígio em seu conselho. Em termos estruturais, podemos avaliar o prestígio de determinado pesquisador, enquanto conselheiro, a partir do número de conselhos editoriais que ele faz parte. Isso porque, como apontam Faust \& Wasserman (1992), há estreita relação entre o número de vezes que um dado ator social é escolhido com sua aprovação social, remetendo então, ao quanto ele é desejado pelo público. Nesses termos, operacionalizamos o prestígio de cada pesquisador por meio do número de conselhos do qual faz parte. Por sua vez, se há indícios que o periódico incorpora, pelo menos em parte, o prestígio dos seus conselheiros para si (Feldman, 2008; Hames, 2001; Zedeck, 2008), tomamos como indicador a média da centralidade dos conselheiros (densidade do conselho editorial).

Com efeito, se o periódico congrega conselheiros mais centrais e de maior prestígio, espera-se que ele também seja mais central em termos da quantidade de laços compartilhados com os demais (degree). Ademais, há indícios de que os conselheiros de maior prestígio tendam a privilegiar periódicos de maior reputação. Associando esse comportamento com a participação dos conselheiros em diferentes periódicos, é provável, em primeiro lugar, que exista maior aproximação entre os conselhos de periódicos de maior reputação, gerando assim, um posicionamento privilegiado destes na rede como um todo, o que pode ser captado por meio da centralidade de intermediação (closeness). Em segundo lugar, como há evidências de que os periódicos mais recentes buscam atrair acadêmicos de maior prestígio (vide Feldman, 2008; Hames, 2001), que, por sua vez, se apresentam como conselheiros dos periódicos de maior reputação, anseia-se que esses últimos apresentem maior grau de intermediação (betweenness).

Em face do que apontam Hames (2001), Whitley (1970) e Zedeck (2008), de que a composição do conselho deve repercutir em melhor avaliação do periódico pela 
comunidade acadêmica, esperamos que a densidade do conselho e a centralidade dos periódicos devam influenciar a avaliação dos periódicos em termos de qualidade percebida, assim como em chances de serem mais citados. No caso da qualidade percebida, utilizamos a classificação segundo os estratos do sistema Qualis/Capes. Por essa classificação de periódicos ser colegiada, em que há julgamento dos pares sobre os critérios socialmente válidos do que é um periódico de qualidade, acreditamos que ela carregue carga cerimonial maior do que nosso segundo indicador, o fator de impacto dos periódicos, que é uma medida objetiva de citações recebidas por um periódico em determinado período. A Tabela 2 traz a correlação entre o Qualis e fator de impacto com os indicadores relacionais e composicionais dos periódicos.

\begin{tabular}{|c|c|c|c|c|c|}
\hline Variáveis & Degree & Closeness & Betweenness & Qualis & FI \\
\hline Idade & $0,303 *$ & 0,223 & $0,339 *$ & $0,373 * *$ & $0,584 * *$ \\
\hline Número de Conselheiros & $0,617 * *$ & $0,419 * *$ & $0,651 * *$ & $0,393 * *$ & $0,398 *$ \\
\hline Endogenia & $-0,140$ & $-0,505 * *$ & $-0,221$ & $-0,124$ & $-0,031$ \\
\hline Internacionalização & $-0,004$ & 0,163 & $-0,134$ & $0,487 * *$ & $-0,186$ \\
\hline Degree (Grau) & 1 & $0,737 * *$ & $0,762 * *$ & $0,587 * *$ & $0,588 * *$ \\
\hline Closeness (Proximidade) & $0,737 * *$ & 1 & $0,498 * *$ & $0,480 * *$ & $0,598 * *$ \\
\hline Betweenness (Intermediação) & $0,762 * *$ & $0,498 * *$ & 1 & $0,432 * *$ & $0,521 * *$ \\
\hline Densidade Média & $0,635^{* *}$ & $0,549 * *$ & $0,280 *$ & $0,273 *$ & $0,410 *$ \\
\hline Densidade (Desvio Padrão) & $0,665^{* *}$ & $0,606 * *$ & 0,236 & $0,336 *$ & 0,217 \\
\hline Qualis & $0,587 * *$ & $0,480 * *$ & $0,432 * *$ & 1 & $0,483 *$ \\
\hline Fator de Impacto (FI) & $0,588 * *$ & $0,598 * *$ & $0,521 * *$ & $0,483 *$ & 1 \\
\hline
\end{tabular}

$* \mathrm{p}<0,05 . \quad * * \mathrm{p}<0,01$.

Tabela 2. Correlação entre Atributos dos Periódicos, Posição na Rede e Qualidade.

Antes de entrar na relação entre centralidade e avaliação, merece ser destacado é a correlação moderada entre os dois indicadores de avaliação de periódicos utilizados $(r=0,483)$, Qualis e Fator de Impacto, dado que evidencia a frouxa associação entre a classificação obtida por um determinado periódico no sistema Qualis e o volume de citações atribuídas a ele. Em outras palavras, haja vista que o sistema de classificação Qualis não considera a usabilidade da produção dos periódicos, calculada pelo fator de impacto, ficando restrito a aspectos cerimoniais e formais ligados à estrutura e gestão do periódico, não é exagero afirmar, como já evidenciaram Machado-da-Silva et al. (2008), que existe certo desacoplamento entre avaliações cerimoniais e objetivas dos periódicos na área de administração brasileira. Dessa forma, cabe investigar separadamente quais fatores estão associados à melhor avaliação cerimonial e efetiva dos periódicos.

Começando pelos fatores composicionais, de forma geral, periódicos mais antigos e com maior número de conselheiros tendem a estar mais bem classificados tanto no sistema Qualis, como apresentam maior fator de impacto (FI). A endogenia do 
conselho editorial, por sua vez, não apresentou relação significativa com a avaliação do periódico. Entretanto o grau de internacionalização do conselho está moderadamente relacionado à classificação do periódico no Qualis, apesar de não possuir influência sobre as citações recebidas. Tal fato possibilita levantar a hipótese de que sua composição a partir de membros de renome internacional possa representar uma espécie de estratégia de legitimação dos periódicos com o propósito de melhorar sua avaliação, cerimonialmente captada por meio do Qualis, independentemente de a atuação desses conselheiros se materializar efetivamente em termos de maior citação dos artigos que o periódico publica.

Diferentemente do grau de internacionalização do conselho, os indicadores relacionais apresentaram-se associados com ambos os tipos de avaliação. Os resultados apontaram que aqueles periódicos que apresentaram maior número de laços (degree), que estão mais próximos de todos os demais (closeness) e que estão em posição de intermediação (betweenness) tendem a possuir melhor classificação no Qualis, mas principalmente maior fator de impacto, ou seja, apresentaram tendência de ter seus artigos citados com maior frequência. Assim como apontado na literatura, tais resultados levam a crer que periódicos cujos conselhos editoriais estão centralmente posicionados parecem usufruir de melhor avaliação tanto do comitê da área (vide Qualis), como dos autores, pois efetivamente esses periódicos recebem mais citações. Cabe frisar também que existe uma dupla causalidade entre os indicadores, já que periódicos de maior reputação, que consequentemente tendem a ter maior fator de impacto, atraem pesquisadores de maior prestígio, o que necessariamente reforça a relação entre centralidade do periódico e avaliação.

Indo ao encontro da análise da centralidade dos periódicos, a avaliação da densidade média do conselho editorial, indicado pela média de laços dos conselheiros, parece reforçar a relação entre o fato de o periódico ter conselheiros mais centrais, ou seja, de maior prestígio, com sua classificação no Qualis e com o fator de impacto. No entanto esse resultado não se repetiu quando analisado o desvio padrão do conselho, cuja relação se deu apenas com o Qualis, mas sem efeito sobre as citações. Essa medida demonstra que os periódicos que incorporaram um ou mais conselheiros mais centrais que a média de seu conselho são mais bem avaliados pela comissão do Qualis. Isso está diretamente associado ao que já ressaltaram Feldman (2008) e Hames (2001), do uso que os periódicos mais recentes fazem dos conselheiros para se legitimar. Todavia, como ocorreu com a presença de conselheiros de renome internacional, essa estratégia só foi válida para avaliação cerimonial e não para o efetivo uso do periódico pela área, 
pelo menos de forma imediata. Por esses aspectos, nitidamente percebesse a capacidade que os conselheiros de prestígio têm sobre processos de julgamento dos pares, ressaltando nosso argumento do cerimonialismo que cerca a atividade editorial científica.

\section{Estratos Qualis e seu Condicionamento nos Padrões Relacionais}

Como apontamos no quadro teórico, agrupamos os periódicos de acordo com os estratos do sistema Qualis/Capes na área de administração no Brasil com o objetivo de avaliar se essas diferentes categorias de periódicos apresentam diferentes padrões relacionais. Primeiramente, apresentamos as médias dos indicadores por estrato Qualis, que estão expostas na Tabela 3.

\begin{tabular}{lcccccccc}
\hline Qualis & A2-B1 & B2 & B3 & B4-B5 & Total & F & Sig. & Eta $^{2}$ \\
\hline Densidade Média & 2,2 & 2,3 & 2,3 & 1,6 & 2,0 & 2,42 & 0,08 & 0,16 \\
Densidade (D.P) & 1,8 & 1,7 & 1,9 & 1,0 & 1,5 & 3,23 & 0,03 & 0,21 \\
Internacionalização & $35 \%$ & $33 \%$ & $12 \%$ & $13 \%$ & $22 \%$ & 4,81 & 0,01 & 0,28 \\
Endogenia & $13 \%$ & $27 \%$ & $25 \%$ & $22 \%$ & $21 \%$ & 0,79 & 0,51 & 0,06 \\
Degree (Grau) & 17,8 & 12,0 & 14,2 & 5,0 & 11,5 & 9,20 & 0,00 & 0,43 \\
Closeness (Proximidade) & 38,8 & 36,6 & 37,0 & 29,9 & 34,9 & 4,99 & 0,01 & 0,29 \\
Betweenness (Closeness) & 31,4 & 15,0 & 24,0 & 1,2 & 16,3 & 4,18 & 0,01 & 0,25 \\
\hline
\end{tabular}

Tabela 3. Média dos Indicadores dos Relacionamentos por Estrato Qualis.

Com exceção da endogenia, todos os indicadores variaram em função da classificação Qualis (vide teste F e Sig.), sendo essa variação maior entre as variáveis relacionais e o grau de internacionalização dos periódicos (maiores $\operatorname{Eta}^{2}$ ). Vale destacar que a diferença entre o grau de internacionalização dos periódicos nos estratos superiores, A2-B1 e B2, em relação aos demais é significativa, evidenciando que o interesse por essa questão parece estar restrito ou, condicionado, por periódicos mais conceituados no sistema Qualis. Cabe ressaltar também, assim como já apontamos, que alguns periódicos conseguiram melhor avaliação provavelmente por ter em seu conselho pesquisadores de renome internacional, já que esse critério é considerado pela comissão do Qualis/Capes.

Além do grau de internacionalização, periódicos classificados como A2-B1, em média, apresentaram maior número de laços, maior intermediação e maior indicador de proximidade, o que vai ao encontro de nosso argumento de que os conselheiros de maior prestígio, em termos de maior centralidade, buscam periódicos de melhor reputação.

No que ainda tange a centralidade, movimento interessante se dá na observação do estrato intermediário B3. Apesar de menos centrais que os dos estratos A2-B1, os periódicos do Qualis B3 se apresentaram mais centrais do que aqueles classificados 
no estrado B2. Tal situação traz indícios de que periódicos desse estrato estão buscando conselheiros mais centrais. Essa tendência de tentar se posicionar de forma privilegiada por parte dos periódicos do Qualis B3 é reforçada quando observado que tal estrato também apresentou valores superiores em quase todos os demais indicadores, se comparados com o estrato B2. Por exemplo, periódicos do Qualis B3 tiveram maior média no desvio padrão na densidade dos conselhos do que periódicos de todos os outros estratos, o que pode indicar interesse mais intenso por conselheiros que participam de vários conselhos editoriais. Entendendo que esses conselheiros têm maior prestígio na academia, parece haver interesse desses periódicos em se legitimar por meio deles, já que a composição do conselho editorial é um dos critérios de avaliação. Diferentemente do estrato B3, aqueles periódicos que estão no estrato B4-B5 apresentaram valores inferiores para a grande maioria dos indicadores, indicando que suas relações com outros periódicos, por meio da composição dos conselhos, tendem a ser periféricas e de menor intensidade.

\begin{tabular}{lccccc}
\hline Qualis & n & Internos & Externos & E-I Index & $\begin{array}{c}\text { Proporção de } \\
\text { Laços }\end{array}$ \\
\hline A2-B1 & 9 & 24 & 85 & 0,560 & $22 \%$ \\
B2 & 10 & 28 & 97 & 0,552 & $24 \%$ \\
B3 & 8 & 18 & 75 & 0,613 & $20 \%$ \\
B4-B5 & 14 & 40 & 105 & 0,448 & $34 \%$ \\
\hline Total & 41 & 110 & 362 & 0,512 & $100 \%$ \\
\hline E-I Index & & & 0,450 & & \\
\hline
\end{tabular}

Obs: Padrão de heterofilia não foi significativo.

Tabela 4. Padrões Relacionais entre Periódicos por Qualis.

Além dos indicadores de centralidade e posicionamento que discutimos anteriormente, outro aspecto referente ao padrão relacional dos periódicos que vale notar diz respeito à proporção de conselheiros que atuam, ao mesmo tempo, em conselhos editoriais de periódicos de diferentes estratos do sistema Qualis (vide dados da Tabela 4 e Figura 2).

Os resultados apontam a existência de tendência de heterogenia na composição dos conselhos editoriais, já que a frequência de laços de conselheiros compartilhados entre periódicos de estratos diferentes é maior do que com aqueles que fazem parte do mesmo estrato (vide E-I Index positivo para todos os Qualis e maior frequência de laços externos que internos). 


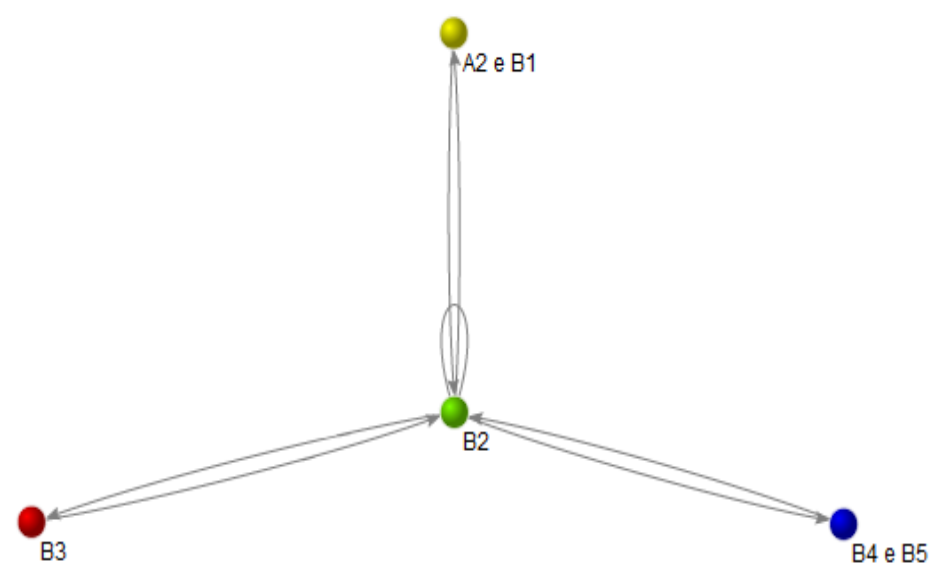

Figura 2. Rede de Relações entre Estratos Qualis.

Para deixar mais evidente a tendência de heterofilia nos relacionamentos entre conselhos editoriais de periódicos de diferentes estratos, podemos observar a Figura 2. Periódicos que fazem parte do estrato A2-B1 compartilham conselheiros com maior frequência com periódicos do Qualis B2 do que com os demais. Já os periódicos do estrato $\mathrm{B} 2$, além de se relacionarem mais intensamente entre si (vide looping), aparecem como elo entre os estratos inferiores, B3 e B4-B5, com os estratos superiores, A2-B1. Essa configuração das posições dos conselhos editoriais a partir dos estratos evidencia que há hierarquização entre periódicos, ressaltando uma diferenciação de status entre eles. Nesse sentido, sob uma ótica individual de análise, podemos entender que conselheiros que fazem parte de conselhos editoriais de periódicos mais bem classificados (A2 e B1), dificilmente fazem parte da composição de conselhos em estratos inferiores de classificação (B3, B4 e B5).

\section{Conselheiros, Instituições de Ensino Superior e a Escolha Preferencial}

Para finalizar nossa análise, ilustramos nosso argumento de que alguns pesquisadores e instituições tendem a ser escolhidos em maior frequência que os demais, o que gera um padrão próximo ao de escolha preferencial (vide Barabasi \& Albert, 1999 e especificamente Moody, 2004; Newman, 2001; Rossoni \& Guarido Filho, 2009; Rossoni, Guarido Filho \& Machado-da-Silva, 2010, para esse fenômeno na academia). Em poucas palavras, enfatizamos que, quanto maior reputação e prestígio os pesquisadores e instituições têm no campo científico, maior a tendência de serem reconhecidos e escolhidos como membros de conselhos editoriais (vide Merton, 1968, 1988; DiPrete \& Eirich, 2006).

Para tanto, apresentamos na Figura 3, em primeiro lugar, a distribuição de frequência do número de conselheiros de cada instituição de ensino superior ou organização em que estão afiliados. Como pode ser observado, existe um processo 
de estratificação na escolha de conselheiros: há muitas instituições com um ou poucos conselheiros nos periódicos da amostra, ao passo que poucas apresentam elevado número de conselheiros nos periódicos. A título de ilustração, as 12 instituições com maior número de conselheiros agregam $47 \%$ das participações nos conselhos editoriais; uma delas, a Universidade de São Paulo (USP), maior do Brasil, reúne $10 \%$ dos conselheiros.

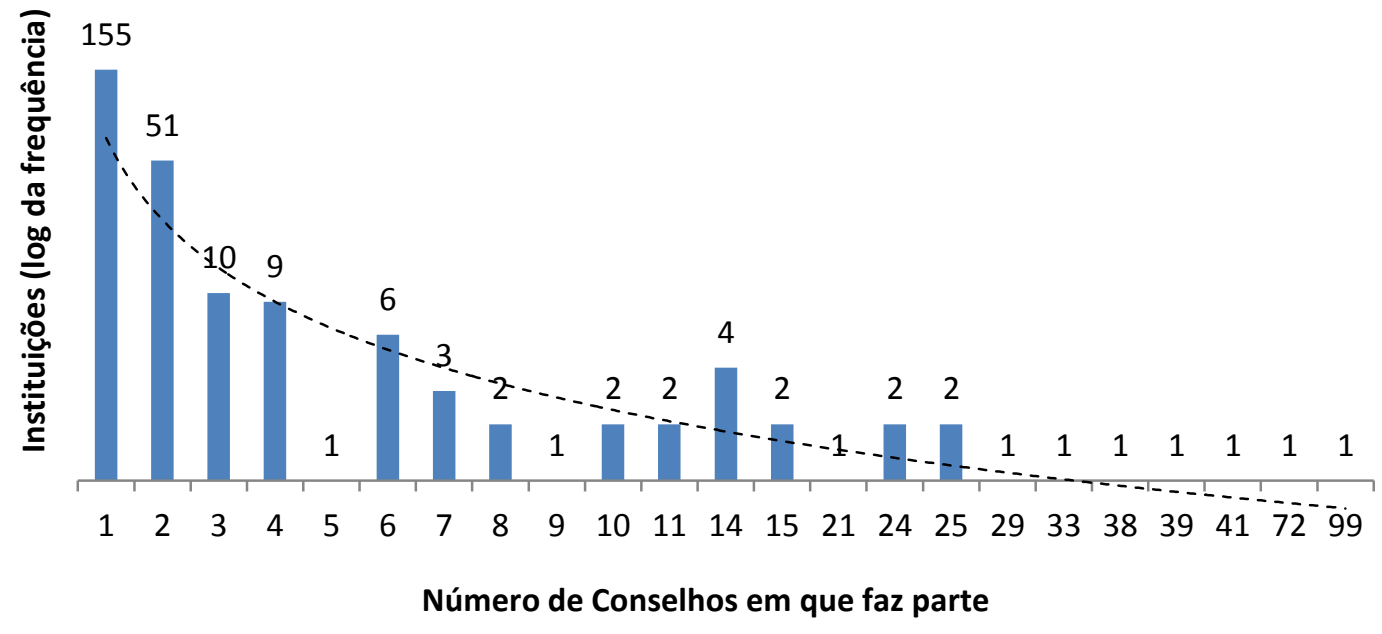

Figura 3. Distribuição de Instituições de Ensino em Conselhos Editoriais.

Além do prestígio, tradição e tamanho dos programas de pós-graduação e pesquisa em administração dessas instituições, a distribuição de conselheiros é influenciada pela concentração de periódicos em uma única unidade federativa no Brasil, o Estado de São Paulo, que abarca $41 \%$ dos periódicos analisados. Tal situação pode ser justificada em razão da facilidade e proximidade de acesso na formação de laços (vide Rossoni \& Graeml, 2009).

Já na Figura 4, está representada a distribuição de frequência dos conselheiros, em geral pesquisadores, quanto ao número de conselhos em que são membros. Verifica-se que a frequência de conselheiros decresce exponencialmente em relação ao aumento de participação em conselhos editoriais, de tal modo que a grande maioria deles está envolvida somente em um único conselho, enquanto um pequeno número deles aparece vinculado a 5 ou mais conselhos editoriais. Esse último grupo é composto por 13 conselheiros que acabam por se posicionar mais centralmente, na medida que representam $8 \%$ do total de participações nos periódicos pesquisados. Comum entre eles está 0 fato de serem todos pesquisadores experientes. Contudo o principal destaque se dá quanto ao vínculo que mantêm ou mantiveram com a associação da academia brasileira em 
Administração (Anpad) e outras entidades oficiais de avaliação da pós-graduação (Capes e CNPq).

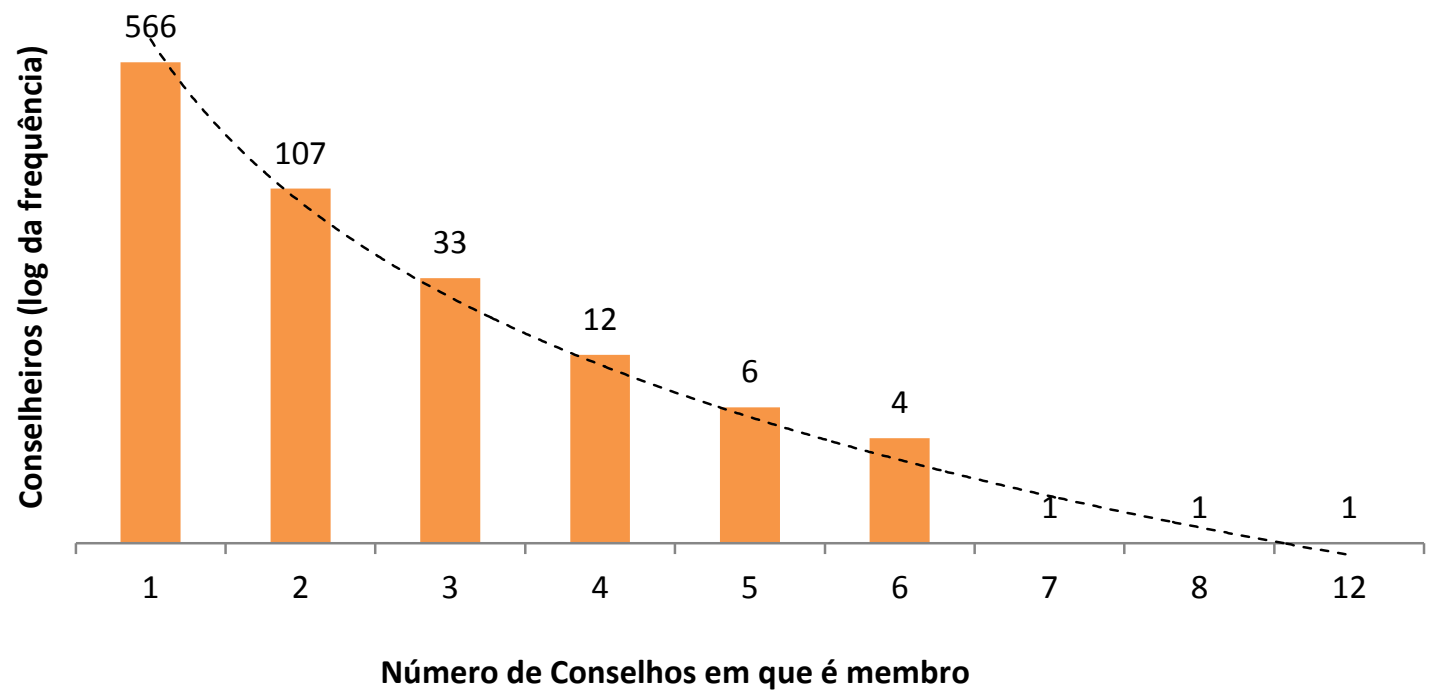

Figura 4. Distribuição de Conselheiros em Conselhos Editoriais.

Esses resultados demonstram que indivíduos bem posicionados em esferas socialmente legitimadas, assim como naquelas oficialmente reconhecidas do campo acadêmico tendem a ser centrais nos conselhos editoriais. Essa posição destacada de alguns pesquisadores remete ao prestígio que possuem. Consequentemente possibilita que sejam mais valorizados pelos conselhos de periódicos, levando-os a serem assediados de forma desproporcional. Como esses convites culminam em aceites por parte dos conselheiros, eles acabam apresentando vários laços, mesmo sem a exigência de presença física em tais círculos.

O destaque desses conselheiros preferencialmente referenciados não se reduz a frequência de conselhos que atuam: ela também envolve a posição que esses têm perante o conjunto de periódicos. Para evidenciar isso, na Figura 5 expomos a rede de relações entre conselheiros mais centrais e periódicos. Nela, é possível verificar que um número reduzido de pesquisadores (nós azuis) permitiu que 29 dos 41 periódicos analisados (nós vermelhos) estivessem conectados entre si em um único componente. Ou seja, mesmo estes pesquisadores não fazendo parte do conselho editorial de todos os periódicos, eles interconectam a maioria deles, principalmente aqueles mais centrais. Por causa do prestígio desses pesquisadores, que se aglutinaram em torno de grande parte dos periódicos, evidencia-se aquilo que chamamos metaforicamente de institucionalização da onipresença: indivíduos, enquanto pertencentes à determinada posição social, mesmo não podendo estar fisicamente em vários lugares ao mesmo tempo, exercem seu papel, mesmo que meramente cerimonial, em inúmeras organizações sociais. 


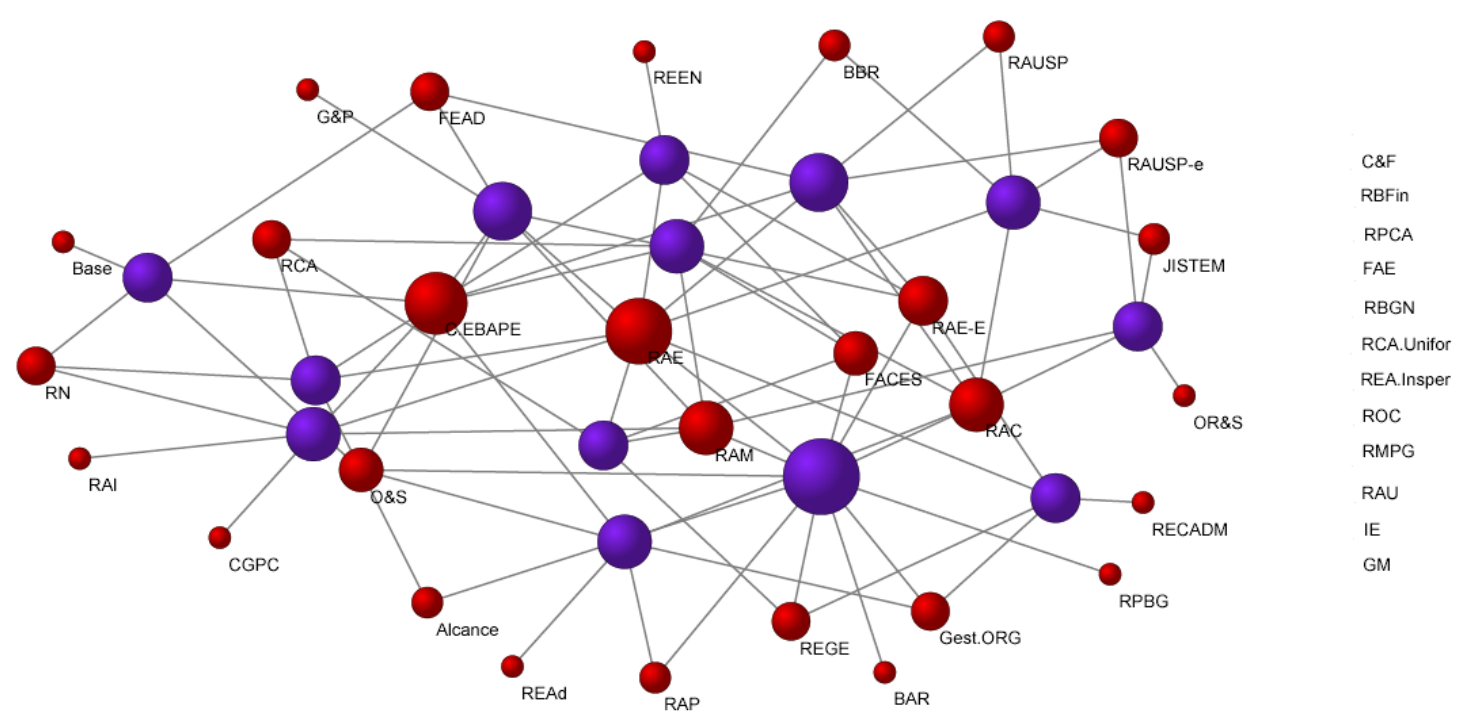

Figura 5. Rede de Relações entre Periódicos e os Treze Conselheiros Mais Centrais.

\section{Comentários Finais}

O objetivo deste estudo foi analisar os periódicos brasileiros da área de administração a partir dos relacionamentos estabelecidos entre eles por meio dos membros de seus conselhos editoriais. Por meio da composição da rede de conselhos dos periódicos, evidenciamos que há relação significativa entre a centralidade e densidade dos conselhos editoriais com o indicador de qualidade percebida, obtida por meio do sistema Qualis de avaliação de periódicos brasileiro. Em menor grau, também foi constatada influência sobre o fator de impacto, indicador associado ao uso de tais periódicos. Esses resultados evidenciaram o que chamamos de institucionalização da onipresença nos conselhos editoriais de periódicos brasileiros, fenômeno associado à existência de cerimonialismo no papel de conselheiros. Isso porque os resultados apontaram que a composição dos conselhos editoriais parece funcionar como mecanismo de legitimação dos periódicos, sem relação imediata com o caráter técnico associado à efetividade da função quanto ao processo editorial. Em certo grau, isso explica porque o prestígio está mais associado à qualidade percebida do que com um indicador mais objetivo, vinculado às citações, como é o caso do fator de impacto.

Tais resultados remetem a algumas implicações de natureza teórica e prática. Em termos teóricos, primeiramente eles nos levam a reafirmar a tese mertoniana de que a ciência, mais do que um sistema racionalmente orientado para a construção do conhecimento de forma objetiva, é um sistema social impregnado de crenças e valores que acabam condicionando o julgamento, por exemplo, de quais periódicos são legitimamente aceitos como de melhor qualidade. Em segundo lugar, se a 
ciência é um sistema social, naturalmente há estratificação dos pesquisadores em termos de status e prestígio. Pressupondo que essa estratificação seja legítima, periódicos que apresentam pesquisadores de maior prestígio e status tendem a ter maior facilidade de serem reconhecidos como de qualidade diferenciada (Feldman, 2008; Hames, 2011). Isso também ficou evidente pela relação entre centralidade dos conselhos editoriais com os indicadores de qualidade e impacto dos periódicos. Em terceiro lugar, nossos resultados apontam que a estratificação dos pesquisadores, e também dos institutos de pesquisa, levam àqueles que apresentam maior prestígio a serem escolhidos preferencialmente, de modo que uma pequena porção desses pesquisadores está presente em grande parte dos conselhos editoriais. Por decorrência, como o prestígio dos pesquisadores está associado à centralidade, naturalmente eles tendem a aglomerar grande parte dos periódicos em uma única rede, aparentando a onipresença que argumentamos neste artigo.

Do ponto de vista prático, adotamos um tom normativo, em que propomos mudanças no processo de seleção dos conselheiros devido à demasiada concentração de indivíduos afiliados em número reduzido de instituições e ao número pequeno de pesquisadores concentrando grande parte dos espaços disponíveis nos conselhos. Se os periódicos realmente zelam pela qualidade do conteúdo publicado, a política de seleção dos membros do conselho editorial deve primar por aumentar o grau de diversidade na composição dos conselhos, focando principalmente o interesse, disponibilidade e capacidade de contribuir com seu processo editorial. Tais medidas também não isentam os conselheiros $\mathrm{e}$ pesquisadores de qualquer responsabilidade. Pelo contrário, se esperamos que a prática da participação puramente cerimonial em conselhos editoriais seja banida, pesquisadores devem aceitar fazer parte de conselhos de periódicos somente quando tiverem condições de atuarem efetivamente.

\section{Referências}

Addis, E., \& Villa, P. (2003). The editorial boards of Italian economic journals: Women, gender, social networking. Feminist Economics, 9(1), 75-91.

Barabasi, A., \& Albert, R. (1999). Emergence of scaling in random networks. Science, 286, 509-512.

Bedeian, A. G. (2003). The Manuscript Review Process: The Proper Roles of Authors, Referees, and Editors. Journal of Management Inquiry, 12(4), 331-338. 
Bedeian, A. G. (2004). Peer Review and the Social Construction of Knowledge in the Management Discipline. Academy of Management Learning and Education, 3(2), 198-216.

Bedeian, A. G., Van Fleet, D. D., \& Hyman, H. H. (2009). Scientific achievement and editorial-board membership. Organizational Research Methods, 12(2), 211-238

Blau, P. M. (1962). Patterns of Choice in Interpersonal Relations. American Sociological Review, 27(1), 41-55.

Chan, K. C., Fung, H. G., \& Lai, P. (2005). Membership of Editorial Boards and Rankings of Schools with International Business Orientation. Journal of International Business Studies, 36 (4), 452-469.

Coordenação de Aperfeiçoamento de Pessoal de Nível Superior. (2007). Avaliação de periódicos científicos de administração, ciências contábeis e turismo (Relatório do processo de avaliação), Brasília, DF, Capes.

Cole, J., \& Cole, S. (1973). Social stratification in science. Chicago: University of Chicago Press.

Crandall, R. (1997). How qualified are editors? American Psychologist, 32(7), 578579.

Crane, D. (1967). The gatekeepers of science: some factors affecting the selection of articles for scientific journals. American Sociologist, 2(4), 195-201.

Cronin, B. (1984). The citation process: the role and significance of citations in scientific communication. London: Taylor Graham.

DiPrete, T. A., \& Eirich, G. M. (2006). Cumulative Advantage as a Mechanism for Inequality: A Review of Theoretical and Empirical Developments. Annual Review of Sociology, 32, 271-297.

Faust, K., \& Wasserman, S. (1992). Centrality and Prestige: A Review and Synthesis. Journal of Quantitative Anthropology, 4(1), 23-78.

Feldman, D. C. (2008). Building and maintaining a strong editorial board and cadre of ad hoc reviewers. In Y. Baruch, A. M. Konrad, H. Aguinis, \& W. H. Starbuck (Eds.), Opening the black box of editorship (pp. 68-74). New York: PalgraveMacmillan.

Fogarty, T. J., \& Liao, C. H. (2009). Blessed are the Gatekeepers: a longitudinal study of the editorial boards of the Accounting Review. Issues in Accounting Education, 24(3), 299-318. 
Garfield, E. (1972). Citation analysis as a tool in journal evaluation. Science, 178(4070), 471-479.

Gilbert, N. (1977). Editorial board membership. American Psychologist, 32(12), 1109-1110.

Hames, I. (2001). Editorial boards: realizing their potential. Learned Publishing, $14(4), 247-256$.

Hardin, W. G., Beauchamp, C. F., Liano, K., \& Hill, M. (2006). Research and Real Estate Editorial Board Membership. Journal of Real Estate Practice and Education, $9(1), 1-18$.

Hitt, M. A. (2009). Editorial judgments, quality scholarship, and the Academy of Management's Journals. Organizational Research Methods, 12(2), 253-258.

Kaufman, G. G. (1984). Rankings of finance departments by faculty representation on editorial boards of professional journals: A note. The Journal of Finance, 39(4), 1189-1197.

Kuhn, T. S. (1970). The structure of scientific revolutions (2nd ed.). Chicago: University of Chicago Press.

Kirschbaum, C., \& Mascarenhas, A. O. (2009). Nos limites da autonomia: reflexões sobre práticas de blind review e editoria de revistas científicas em administração no Brasil. RAE Eletrônica, 8(1), art. 5.

Krackhardt, D., \& Stern, R. (1988). Informal Networks and Organizational Crises: An experimental simulation. Social Psychology Quarterly, 51(2), 123-140.

Lindsey, D. (1976). Distinction, achievement, and editorial board membership. American Psychologist, 31(11), 799-804.

Lindsey, D., \& Lindsey, T. (1978). The outlook of journal editors and referees on the normative criteria of scientific craftsmanship. Quality \& Quantity, 12(1), 45-62.

Machado da-Silva, C. L., Guarido Filho, E. R., Rossoni, L., \& Graeff, J. F. (2008). Periódicos Brasileiros de Administração: Análise Bibliométrica de Impacto no Triênio 2005-2007. Revista de Administração Contemporânea Eletrônica (RAC-E), 2(3), 351-373.

Mcphearson, M., Smith-Lovin, L., \& Cook, J. M. (2001). Birds of a Feather: Homophily in Social Networks. Annual Review of Sociology, 27, 415-444.

Meadows, A. J. (1998). Communicating research. San Diego: Academic Press.

Merton, R. K. (1968). The Matthew effect in science. Science, 159(3810), 56-63. 
Merton, R. K. (1988). The Matthew effect in science, II: cumulative advantage and the symbolism of intellectual property. Isis, 79(4), 606-623.

Merton, R. K. (1996). On social structure and science. Chicago: Chicago Univ. Press.

Meyer, J. W., \& Rowan, B. (1977). Institutionalized Organizations: Formal Structure as Myth and Ceremony. American Journal of Sociology, 83(2), 340-363.

Mittermaier, L. J. (1991). Representation on the Editorial Boards of Academic Accounting Journals: An Analysis of Accounting Faculties and Doctoral Programs. Issues in Accounting Education, 6(2), 221-238.

Moed, H. F. (2005). Citation analysis in research evaluation. Netherlands: Springer. Moody, J. (2004). The structure of a social science collaboration network: disciplinary cohesion from 1963 to 1999. American Sociological Review, 69(2), 213238.

Newman, M. E. J. (2001). The structure of scientific collaboration networks. Proceedings of National Academic Sciences, 98(2), 404-409.

Ozbilgin, M. (2004). "International" human resource management: Academic parochialism in editorial boards of the "top" 22 journals on international human resource management. Personnel Review, 33(2), 205-221.

Parker, L. D. (2007). Developing research journals and qualitative inquiry: the role of the editorial board. Qualitative Research in Accounting \& Management, 4(3), 168-182.

Rossoni, L., \& Graeml, A. R. (2009). A Influência da Imersão Institucional e Regional na Cooperação entre Pesquisadores no Brasil. Redes - Revista Hispana para el Análisis de Redes Sociales, 16, 228-249.

Rossoni, L., \& Guarido Filho, E. R. (2009). Cooperação entre Programas de PósGraduação em Administração no Brasil: Evidências Estruturais em Quatro Áreas Temáticas. Revista de Administração Contemporânea, 13(3), 366-390.

Rossoni, L., Guarido Filho, E. R., \& Machado-da-Silva, C. L. (2010). A Questão da Agência em Redes Acadêmicas de Pesquisa: Centralidade, Produtividade e Escolha Preferencial. Redes - Revista Hispana para el Análisis de Redes Sociales, 19, 95121.

Rousseau, R. (2002). Journal evaluation: technical and practical issues. Library Trends, 50(3), 418-439. 
Rynes, S. L. (2006). Getting on board with AMJ: Balancing quality and innovation in the review process. Academy of Management Journal, 49(6), 1097-1102.

Smigel, E., \& Ross, H. (1970). Factors in the editorial decision. American Sociologist, 5(1), 19-21.

Souza, E. P., \& Paula, M. C. S. (2002). Qualis: a base de qualificação dos periódicos científicos utilizada na avaliação CAPES. InfoCAPES, 10(2), 6-24.

Tutarel, O. (2004). Composition of the editorial boards of leading medical education journals. BMC Medical Research Methodology, 4, art. 3.

Wasserman, S., \& Faust, K. (1994). Social Network Analysis: Methods and Applications. Cambridge: Cambridge University Press.

Weber, M. (1996). A ética protestante e o espírito do capitalismo. (11a. ed.). São Paulo: Pioneira.

Whitley, R. (1970). The operation of science journals: two case studies in British social science. Sociological Review, 18(2), 241-258.

Zedeck, S. (2008). Editing a top academic journal. In Y. Baruch, A. M. Konrad, H. Aguinis, \& W. H. Starbuck (Eds.), Opening the black box of editorship (pp. 145156). New York: Palgrave-Macmillan.

Apêndice A: Lista de Periódicos Avaliados.

\begin{tabular}{lcccccccc}
\hline Sigla & Qualis & Início & Idade & N.Cons. ${ }^{*} \begin{array}{c}\text { Fator de } \\
\text { Impacto }\end{array}$ & Intern. ${ }^{* *}$ & Endogenia & Degree \\
\hline Alcance & B3 & 1997 & 13 & 20 & & $10 \%$ & $35 \%$ & 16 \\
BAR & A2 & 2004 & 6 & 19 & 0,23 & $89 \%$ & $0 \%$ & 13 \\
Base & B2 & 2004 & 6 & 12 & 0,03 & $33 \%$ & $17 \%$ & 7 \\
BBR & B2 & 2004 & 6 & 22 & 0,09 & $50 \%$ & $9 \%$ & 11 \\
C\&F & B1 & 1989 & 21 & 16 & 0,11 & $44 \%$ & $31 \%$ & 2 \\
C.EBAPE & B1 & 2003 & 7 & 67 & 0,06 & $13 \%$ & $6 \%$ & 24 \\
CGPC & B5 & 1997 & 13 & 43 & & $19 \%$ & $23 \%$ & 8 \\
FACES & B3 & 2002 & 8 & 25 & & $28 \%$ & $4 \%$ & 20 \\
FAE & B4 & 1998 & 12 & 12 & & $17 \%$ & $0 \%$ & 1 \\
FEAD & B4 & 2006 & 4 & 15 & & $20 \%$ & $0 \%$ & 14 \\
G\&P & B3 & 1999 & 11 & 8 & & $13 \%$ & $38 \%$ & 8 \\
Gerenciais & B5 & 2002 & 8 & 4 & & $0 \%$ & $25 \%$ & 9 \\
Gest.ORG & B3 & 2003 & 7 & 11 & 0,10 & $0 \%$ & $55 \%$ & 14 \\
GM & B5 & 1999 & 11 & 22 & & $9 \%$ & $45 \%$ & 1 \\
IE & B5 & 2000 & 10 & 14 & & $0 \%$ & $50 \%$ & 2 \\
JISTEM & B2 & 2004 & 6 & 28 & 0,00 & $54 \%$ & $25 \%$ & 12
\end{tabular}




\begin{tabular}{|c|c|c|c|c|c|c|c|c|}
\hline Sigla & Qualis & Início & Idade & N.Cons. ${ }^{*}$ & $\begin{array}{l}\text { Fator de } \\
\text { Impacto }\end{array}$ & Intern. ${ }^{* *}$ & Endogenia & Degree \\
\hline O\&S & B2 & 1993 & 17 & 22 & 0,29 & $14 \%$ & $23 \%$ & 21 \\
\hline OR\&A & B2 & 1989 & 21 & 14 & 0,01 & $29 \%$ & $14 \%$ & 11 \\
\hline RAC & B1 & 1997 & 13 & 26 & 0,56 & $15 \%$ & $0 \%$ & 27 \\
\hline RAE & B1 & 1961 & 49 & 102 & 0,97 & $9 \%$ & $21 \%$ & 30 \\
\hline RAE-E & B1 & 2002 & 8 & 52 & 0,36 & $6 \%$ & $27 \%$ & 24 \\
\hline RAI & B3 & 2004 & 6 & 26 & 0,00 & $8 \%$ & $15 \%$ & 12 \\
\hline RAM & B1 & 2000 & 10 & 34 & 0,04 & $29 \%$ & $15 \%$ & 25 \\
\hline RAP & $\mathrm{A} 2$ & 1967 & 43 & 16 & 0,16 & $25 \%$ & $19 \%$ & 13 \\
\hline RAU & B5 & 2003 & 7 & 5 & & $0 \%$ & $100 \%$ & 0 \\
\hline RAUSP & B2 & 1976 & 34 & 14 & 0,30 & $14 \%$ & $57 \%$ & 12 \\
\hline RAUSP-e & B2 & 2008 & 2 & 13 & & $15 \%$ & $54 \%$ & 13 \\
\hline RBFin & B1 & 2003 & 7 & 18 & & $44 \%$ & $0 \%$ & 5 \\
\hline RBGN & B3 & 1999 & 11 & 14 & & $21 \%$ & $0 \%$ & 4 \\
\hline RCA & B3 & 1998 & 12 & 26 & 0,00 & $12 \%$ & $35 \%$ & 14 \\
\hline RCA.Unifor & B4 & 1995 & 15 & 12 & & $25 \%$ & $17 \%$ & 4 \\
\hline REA.Insper & B4 & 2002 & 8 & 11 & & $9 \%$ & $9 \%$ & 7 \\
\hline REAd & $\mathrm{B} 2$ & 1995 & 15 & 11 & 0,08 & $55 \%$ & $18 \%$ & 9 \\
\hline RECADM & B5 & 2002 & 8 & 11 & & $0 \%$ & $0 \%$ & 7 \\
\hline REEN & B4 & 2008 & 2 & 14 & & $43 \%$ & $21 \%$ & 9 \\
\hline REGE & B3 & 1994 & 16 & 17 & 0,09 & $18 \%$ & $41 \%$ & 20 \\
\hline RMPG & B5 & 2007 & 3 & 19 & & $21 \%$ & $0 \%$ & 3 \\
\hline $\mathrm{RN}$ & B3 & 1996 & 14 & 107 & 0,00 & $1 \%$ & $5 \%$ & 20 \\
\hline ROC & B5 & 2005 & 5 & 7 & & $14 \%$ & $14 \%$ & 4 \\
\hline RPBG & B1 & 2002 & 8 & 73 & & $73 \%$ & $14 \%$ & 15 \\
\hline RPCA & B5 & 2007 & 3 & 6 & & $0 \%$ & $0 \%$ & 1 \\
\hline
\end{tabular}

* N.Cons.: número de conselheiros do periódico.

** Intern.: grau de internacionalização do conselho editorial. 